\title{
Pemungutan Pektin dari Kulit dan Amapas Apel Secara Ekstraksi
}

\author{
Purwo Subagyo dan Zubaidi Achmad \\ Jurusan Teknik Kimia, Fakultas Teknologi Industri \\ Universitas Pembangunan Nasional "Veteran" Yogyakarta \\ Jln. Swk 104 Lingkar utara, Condongcatur, Yogyakarta, 55283. \\ Telp./Fax.: 0274486 889. e_mail: subagyo_p@yahoo.com
}

\begin{abstract}
Abstrak
Apel dikonsumsi sebagai buah segar maupun produk olahan. Sebagai produk olahan (buah kaleng, jus, sari buah), apel menyisakan limbah berupa kulit dan ampas, yang kebanyakan digunakan subsitusi pupuk dan pakan ternak atau dibuang. Kandungan pektin dalam buangan tersebut belum termanfaatkan. Penelitian ini memanfaatkan limbah tersebut untuk dipungut kandungan pektinnya. Apel dikupas, sedang daging buah diperas, dipisahkan sari buahnya dan diambil ampasnya. Kulit dan ampas dikeringkan, kemudian diekstraksi dalam labu leher tiga dengan solven air pada suasana asam (dipakai, $\mathrm{HCl}$ ). Ekstraksi dilakukan dengan variasi suhu $(60,70$, 80,90 dan $\left.100{ }^{\circ} \mathrm{C}\right), \mathrm{pH}(2 ; 2,5 ; 3 ; 3,5$ dan 4$)$, waktu $(30,60,90,120$ dan 150$)$ menit. Ekstrak disaring dalam keadaan panas, kemudian ditambahkan Aceton hingga terbentuk endapan. Endapan dicuci dengan Alkohol hingga netral dan dikeringkan dalam oven sampai beratnya kanstan, sebagai pektin kering. Kondisi operasi optimal dicapai pada suhu eketraksi $90{ }^{\circ} \mathrm{C}$, dengan $\mathrm{pH}$ larutan untuk ampas $(3,5)$, untuk larutan kulit $\mathrm{pH} 3$, dan waktu operasi 90 menit. Pektin kering yang terpungut (rerata) pada kondisi operasi tersebut adalah 13,940\% (berat) untuk ampas dan 12,897 \% (berat) untuk kulit apel.Perlu dilakukan uji kelayakan hasil jika pektin tersebut akan dimanfaatkan sebagai subsitusi bahan pangan, bahan pengobatan dan industri farmasi.
\end{abstract}

Kata kunci: ampas apel,buangan (limbah), ekstraksi, kulit apel, pektin.

\section{Pendahuluan}

Tanaman apel merupakan salah satu jenis tanaman buah yang banyak dan mudah tumbuh di daerah tropis, termasuk Indonesia, diantaranya di daerah Batu (Malang), Pasuruan, Lumajang dan beberapa dataran tinggi yang tidak banyak berkabut.

Ada beberapa jenis buah apel yang banyak dikonsumsi, sedangkan beberapa lainnya digunakan sebagai produk olahan, antara lain sebagai buah kaleng, "manisan apel ", sirup, jus dan sari buah. Buangan dari proses olahan yang berupa kulit dan ampas, selama ini hanya digunakan sebagai subsitusi pakan ternak dan pemupukan tanaman. Dari beberapa analisa yang dilakukan oleh peneliti terdahulu, dinyatakan bahwa buangan tersebut masih banyak mengandung pektin. Pektin banyak digunakan sebagai bahan pembuatan jeli dan bahan pencampur pembuatan agar-agar rasa buah. Maka jika pektin dalam buangan tersebut dapat dipungut tentu akan ada peningkatan nilai ekonomis dari sekedar limbah. Operasi pemungutan yang banyak digunakan adalah dengan Ekstraksi.

\subsection{Apel}

Tanaman apel tumbuh di daerah dengan ketinggian 700 - 1200 meter diatas permukaan laut, suasana kering atau basah, asal tidak banyak turun kabut.

Buah apel mempunyai banyak manfaat, antara lain sebagai: penurun kolesterol dalam darah, penurun tekanan darah, penstabil gula darah, agen anti kanker, dan buah andalan bagi yang sedang menjalankan diet menurunkan berat badan. Jenis buah apel yang banyak di budidayakan di Indonesia adalah: Rome Beauty, Manalagi, Anna, Princess Noble, Wanglin/Lali Jiwo, Apel Malang dan yang sedang dikembangkan antara lain Winter Banana, Sweet Caroline, dan Jonathan. Kandungan gizi dalam apel beragam. Dalam 100 gram buah terkandung antara lain: Energi 58,00 kal; Karbohidrat 14,90 gram; Kalsium 6,00 mgram; Fosfor 10,00 mg; Besi 1,30 mg, Serat 0,70 mg; Vitamin A 24,00 rpe dan lainnya (Bambang, 1997; Wirakusumah, 1995; Margantan, 2001). Bagian buah yang banyak mengandung pektin adalah ampas (daging buah yang sudah diambil sarinya) berkisar $15-20 \%$ berat dan pada kulit buah berkisar 4-7\% berat (Kirk n Othmer, 1958; Suhardi, 1997; Winarno, 1984;).

\subsection{Pektin}

Pektin (Pechtos, Yunani) umumnya terdapat di dalam dinding sel primer tanaman, disela-sela sellulose dan hemisellulose, dan berfungsi sebagai perekat antara dinding sel yang berdekatan (middle lamella). Pektin atau dikenal sebagai Asam Poligalakturonat, mengandung 3-16\% gugus mektosil, dapat larut dalam air, membentuk jelly dan gula dalam suasana asam.

Senyawa penyusun Pektin, yaitu:

a. Asam Pektat, adalah pektin yang tidak mengandung gugus Metil Ester, biasanya terdapat pada sayuran dan buah yang busuk atau yang terlalu matang. 
Keberadaan dalam tanaman sebagai Kalsium atau Magnesium Pektat

b. Asam Pektina (Pektin), adalah Asam Poligalakturonat, yaitu asam yang mengandung gugus Metil Ester, dapat terikat dengan air membentuk jelly dan gula dalam suasana asam

c. Protopektin, adalah komponen yang tidak larut dalam air, dapat dihidrolisa dan terdespersi menjadi Pektin dan Pektinat. Hal tersebut yang menyebabkan jaringan buah atau sayur menjadi empuk (lunak) saat dimasak dengan air panas.

Beberapa jenis buah-buahan yang mengandung pektin antara lain jeruk, apel, mangga, jambu biji, lobi-lobi, nanas, marmelade dan arbei. Terdapat juga dalam akar gentian, kulit buah, getah dalam kayu, misal pinus penaster (Winarno, 1984).

Pektin tidak larut dalam pelarut organik, kecuali Formamide, Dimethyl Sulfoxide, Dimethyl Formide dan Gliseriol panas. Sebagaimana Polisakarida lainnya, pektin tidak mempunyai titik lebur dan akan terdekomposisi serta menghilang selama pemanasan. Sudut putar optik positifnya tinggi, yaitu $\pm 230 / 20^{\circ} \mathrm{C}$ (Othmer, 1958).

Pektin bermanfaat bagi industri farmasi dan pengobatan. Pada industri farmasi sebagai pengganti plasma darah, pengental, zat pengelmusi dan pensuspensi. Sedangkan dibidang pengobatan antara lain untuk perbaikan otot pencernaan, menurunkan kolesterol dan trigleserida (penyebab penyakit jantung), menghentikan pendarahan internal (diminum) maupun eksternal (dikompres), juga menyerab kelebihan air dalam usus serta mengikat dan menghilangkan racun dalam usus (pada penyakit diare). Biasanya dicampur Kaolin atau antibiotik. Pada industri makanan dimanfaatkan sebagai pembentuk gel, stabilizer dalam ice cream dan sari buah tertentu, pengental dan pelapis puding, serta lainnya.

\subsection{Pemungutan Pektin.}

Pemungutan pektin dilakukan melalui beberapa cara, yaitu (Suhardi, 1997):

a. Sedimentasi (Pengendapan), dimaksudkan untuk memisahkan pektin dari larutannya. Hal ini dilakukan bila pektin hasil di inginkan kering. Yang lazim dilakukan adalah dengan menambahkan Alkohol, Aseton dan Ion Polivalen

b. Pemurnian, dimaksudkan untuk mengisolasi pektin dari komponen ikutan yang tidak di inginkan. Pada pengendapan koloid, endapan yang diperoleh tercampur dengan sisa Alumunium Hidroksida $\left[\mathrm{Al}(\mathrm{OH})_{3}\right]$ yang tidak dapat larut dalam Alkohol. Dalam pencucian, $\mathrm{Al}(\mathrm{OH})_{3}$ diubah menjadi $\mathrm{AlCl}_{3}$ dengan menambahkan $\mathrm{HCl}$. Selanjutnya $\mathrm{AlCl}_{3}$ dan sisa $\mathrm{HCl}$ dicuci dengan Alkohol netral. Pencucian dilakukan dua kali, pertama dengan Alkohol 85\% yang berisi $\mathrm{HCl} 10 \%$ dan kemudian dengan Alkohol 95\%. Pencucian dengan Alkohol Asam dilakukan dua kali sedangkan dengan Alkohol netral dilakukan tiga kali.

c. Ekstraksi, dimaksudkan untuk memungut pektin dengan menambahkan pelarut berupa air (dingin atau panas) atau larutan asam yang dipanaskan, seperti: Asam Sitrat, Asam Tartrat, Asam Laktat, Asam Klorida atau Asam Sulfat.

\subsection{Ektraksi.}

Ekstraksi secara umum adalah operasi perpindahan massa suatu komponen dari suatu padatan ke dalam cairan pelarut, dikenal sebagai ekstraksi padat-cair. Jika suhu pelarut tinggi biasanya waktu ekstraksi yang diperlukan lebih singkat daripada jika digunakan pelarut bersuhu rendah (Brown, 1961).

Tiga (3) faktor penentu dalam ekstraksi pektin adalah: suhu, $\mathrm{pH}$ dan waktu reaksi. Kisaran $\mathrm{pH}$ yang direkomendasikan adalah 1,8-3 tetapi yang sering digunakan adalah pH 2,0-2,8 (Bhatia dkk., 1959; Kertesz, 1951; Othmer, 1958; Suhardi, 1997). Batasan bagi kombinasi kondisi operasi untuk pencapaian optimasi hasil perlu memperhatikan beberapa hal berikut (Bhatia dkk., 1959):

a. Penggunaan $\mathrm{pH}$ rendah tidak boleh dikombinasikan dengan suhu yang tinggi, karena dapat menyebabkan terhidrolisanya pektin yang sudah terdispersi ke solven.

b. Suhu ekstraksi tinggi tidak boleh dikombinasikan dengan waktu ekstraksi yang lama. Karena pada suhu tinggi dan dalam waktu ekstraksi yang lama pektin akan terdegradasi ketika pektin terlepas dari jaringan dinding sel.

\subsection{Pemurnian dan Uji Pektin.}

Ekstrak pektin hasil dibilas dengan Alkohol dan kemudian Air, yang ditujukan untuk menghilangkan sisa-sisa asam yang digunakan dalam ektraksi. Kemudian dilakukan pengeringan dalam oven dengan suhu $37-40{ }^{0} \mathrm{C}$ selama \pm 5 jam, atau dengan spray drying suhu $\pm 60{ }^{0} \mathrm{C}$. Pektin kering selanjutnya ditentukan "jelly grade" nya berdasar jumlah gula yang dibutuhkan pektin untuk membentuk gel.

Standadisasi lain yang perlu dilakukan adalah Setting Time, yaitu waktu yang diperlukan bagi pembentukan gel sejak penambahan bahan-bahan pembentuk gel. Jika gel terbentuk sebelum penambahan selesai maka hasilnya tidak merata (curdle), dikenal sebagai Rapid Setting atau Quick Setting. Jika waktu yang dibutuhkan untuk membentuk gel lama maka hasilnya dikatagorikan sebagai Slow Setting yang ditandai dengan bentuk gel yang lemah atau mudah terdispersi (Afiz, 2010; Bhatia, 1959; Suhardi, 1997; Winarno, 1984).

Standar pektin hasil berdasar fungsinya di bidang pengobatan atau farmasi adalah adanya gugus Metoksi dan Asam Galakturonat, serta harus diperhatikan susut keringnya. Pada kondisi kering pektin boleh mengandung Gugus Metoksi $\left(-\mathrm{OCH}_{3}\right)$ tidak kurang dari 6,7\%; Asam Galakturonat $\left(\mathrm{C}_{6} \mathrm{H}_{10} \mathrm{O}_{7}\right)$ tidak kurang dari $74,0 \%$, sedangkan kandungan gula dan asam 
organik tidak boleh lebih dari 10\% (DepKes RI, 1995; FAO, 1978).

\subsection{Batasan Masalah.}

Batasan masalah yang diambil adalah:

a. Ampas dan kulit apel yang digunakan bukan dari sisa produksi olahan apel tetapi disediakan sendiri dari buah apel jenis Princess Noble, umur 4-5 bulan.

b. Ekstraksi dilakukan labu leher tiga, batch, berpengaduk dengan kecepatan pengadukan \pm 300 rpm dengan solven aquades.

c. Bahan (berat): Solven (volume) $=1: 12$

d. Solven yang digunakan untuk memperoleh pektin kering adalah $\mathrm{HCl}$

6. Tujuan Penelitian

Penelitian ditujukan untuk memungut kandungan pektin dalam ampas dan kulit buah apel dengan cara ektraksi. Variabel operasi yang diamati adalah suhu, $\mathrm{pH}$ dan waktu ekstraksi.

\section{Metodologi.}

\subsection{Bahan baku.}

Ampas dan kulit buah apel disediakan dari buah apel jenis Princess Noble, umur 4-5 bulan, berukuran kecil, warna hijau cerah rasa agak asam dengan aroma yang kuat. Apel diperoleh dari pekebun di daerah Tawangmangu, Jawa Tengah. Kandungan air buah $86,35 \%$ (berat).

Buah dikuliti sedangkan daging buah di blender. Kandungan air pada kulit (kering) 13,15\% dan pada ampas (kering) 19,32\%.

\subsection{Bahan Pembantu}

Bahan yang digunakan adalah: Asam Klorida $(\mathrm{HCl})$ sebagai pembuat suasana asam pada larutan, Aseton 50-60\% sebagai pembentuk endapan, Alkohol 90\% sebagai larutan pencuci endapan, Aquades sebagai pelarut dan $\mathrm{NaOH} 0,05 \mathrm{~N}$ sebagai pengatur $\mathrm{pH}$.

\subsection{Alat Penunjang Percobaan.}

Alat penunjang yang digunakan adalah: blender, pisau stainless steel, saringan plastik, labu takar, erlenmeyer, gelas ukur, gelas arloji, $\mathrm{pH}$ meter, kertas saring, pipet kaca, torong Buchener, Eksikator, timbangan listrik, cawan porselen, pemanas listrik (oven), sarung tangan. Rangkaian Alat Percobaan dapat dilihat pada gambar 1 .

\subsection{Cara Penelitian.}

Apel dibersihkan dari kotoran yang terikut, kemudian dikupas tipis. Kulit dan daging buah diblender tanpa penambahan air, dikeringkan dan kemudian dilakukan analisa kadar air. Daging buah sebelum dikeringkan diperas dan kemudian disaring agar sari buah keluar. Bahan berupa lumatan kulit dan ampas apel siap untuk di treatment.

Bahan seberat 20 gram, dimasukkan kedalam labu leher tiga yang sudah di isi aquades kemudian ditambahkan larutan $\mathrm{HCl}$ sebanyak $\mathrm{pH}$ yang divariasikan. Larutan total yang digunakan $240 \mathrm{ml}$. Pengaduk serta pemanas dijalankan. Waktu ekstraksi dihitung saat suhu operasi yang ditentukan tercapai dan dihentikan setelah waktu yang ditetapkan tercapai. Ekstrak disaring dalam keadaan panas, dimasukkan beker-glass dan kemudian ditambahkan Aceton hingga terbentuk endapan. Endapan disaring menggunakan kertas saring pada torong Buchener, dicuci dengan Alkohol hingga netral, dan kemudian dikeringkan dalam oven, sampai didapat berat yang konstan. Hasil, berupa pektin kering kemudian ditentukan prosentasenya secara gravimetri.

Variasi suhu $\left({ }^{0} \mathrm{C}\right)$ yang dilakukan adalah: 60, $70,80,90$ dan 100. Variasi pH: $2,(2,5), 3,(3,5)$, dan 4, sedangkan variasi waktu ekstraksi (menit): 30, 60, 90, 120, dan 150 .

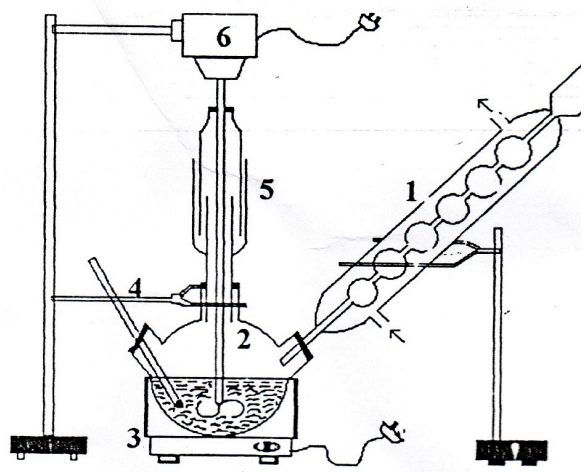

Gambar 1. Rangkaian Alat Ekstraksi

Keterangan Gambar:

(1) Pendingin Balik, (2) Labu leher Tiga, (3) Pemanas Listrik, (4) Termometer, (5) Pengaduk Merkuri, (6) Motor Pengaduk

\section{Hasil dan Pembahasan.}

3.1 Pengaruh Suhu Terhadap Pektin Terpungut. Berat ampas atau kulit apel 20 gram, volume larutan $240 \mathrm{ml}, \mathrm{pH}$ larutan $(2,5)$ dan waktu ekstraksi 90 menit.

Data percobaan digambarkan dalam Gambar 2.

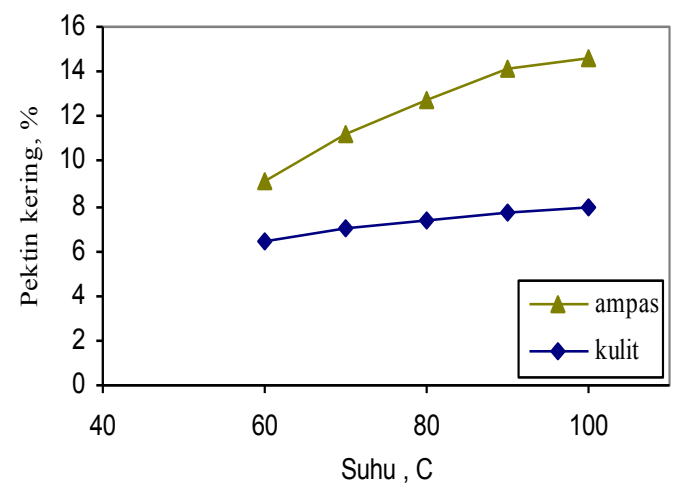

Gambar 2.Pengaruh Suhu Ekstraksi Terhadap Pektin Terpungut 
Dari Gambar 2 terlihat bahwa peningkatan suhu ekstraksi berpengaruh terhadap peningkatan pektin yang terpungut. Hal tersebut diduga karena pada suhu yang semakin tinggi semakin cepat pula pergerakan molekul kedua komponen, sehingga perpindahan massa pektin karena peluruhan dari padatan ke pelarut juga semakin banyak.

Suhu ekstraksi $90{ }^{\circ} \mathrm{C}$ diambil sebagai variabel tetap pada pengamatan variabel $\mathrm{pH}$.

\subsection{Pengaruh pH terhadap Pektin Terpungut.}

Berat ampas atau kulit apel 20 gram, volume larutan $240 \mathrm{ml}$, suhu ekstraksi $90{ }^{0} \mathrm{C}$ dan waktu ekstraksi 90 menit.

Data percobaan digambarkan dalam Gambar 3.

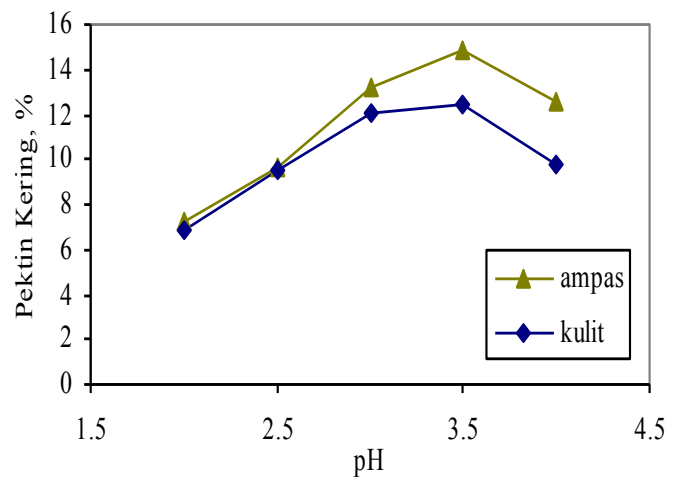

Gambar 3. Pengaruh $\mathrm{pH}$ terhadap Pektin Terpungut.

Dari Gambar 3 terlihat bahwa peningkatan $\mathrm{pH}$ larutan menyebabkan peningkatan prosentase pektin yang terpungut Tetapi terjadi perbedaan perolehan pada ampas dan kulit apel dan hal tersebut diduga karena pengaruh kadar air awal pada bahan. Pektin terlarut dalam air maka semakin banyak air terikat semakin besar pula kandungan pektin yang dapat ditahan dalam bahan. $\mathrm{pH}(3,5)$ pada perlakuan ampas dan $\mathrm{pH} 3$ pada perlakuan kulit apel diambil sebagai variabel tetap pada pengamatan variabel waktu ekstraksi.

\subsection{Pengaruh Waktu Ekstraksi Terhadap Pektin Terpungut}

Berat ampas atau kulit apel 20 gram, volume larutan $240 \mathrm{ml}$, suhu ekstraksi $90{ }^{\circ} \mathrm{C}$ dan $\mathrm{pH}$ larutan ampas apel $(3,50)$ sedang $\mathrm{pH}$ larutan kulit apel 3 .

Data percobaan digambarkan dalam Gambar 4.

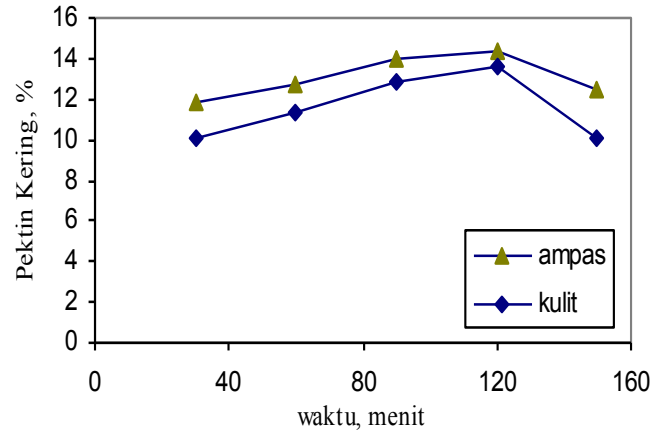

Gambar 4. Pengaruh Waktu Ekstraksi Terhadap Pektin Terpungut

Dari Gambar 4 terlihat bahwa semakin lama waktu ekstraksi semakin banyak pektin pula yang terpungut, tetapi setelah 90 menit terlihat terjadinya penurunan, baik bagi ampas maupun kulit apel menunjukkan kecenderungan peningkatan yang serupa. Hal tersebut diduga karena semakin lama waktu ekstraksi semakin banyak kesempatan solven menyerang struktur protopektin menjadi pektin. Tetapi jika terlalu lama maka pektin yang terbentuk juga akan diserang, sehingga terjadi degradasi pektin yang terjadi.

Dari data percobaan diatas terlihat bahwa hasil pemungutan pektin pada ampas apel lebih besar daripada kulit apel. Hal tersebut sesuai dengan karakteristik keberadaan pektin sendiri, karena pektin banyak terikat pada sela atau antara sellulose dan hemisellulose. Kandungan kedua komponen sellulose tersebut lebih banyak terdapat pada ampas apel.

\section{Penutup.}

Pemungutan pektin dalam ampas dan kulit apel dapat dilakukan dengan cara ekstraksi menggunakan pelarut aquades dan pemurrnian dilakukan dalam suasana asam menggunakan larutan $\mathrm{HCl}$.

Kondisi operasi optimal yang diperoleh yaitu: suhu ekstraksi $90{ }^{0} \mathrm{C}, \mathrm{pH}$ larutan untuk ampas $(3,5)$, untuk larutan kulit $\mathrm{pH} 3$, dalam waktu operasi 90 menit. Pektin yang terpungut (rerata) pada kondisi operasi tersebut adalah 13,940 \% untuk ampas dan 12,897\% untuk kulit apel.

Pektin hasil masih perlu diuji kelayakannya, baik jika akan digunakan sebagai komponen subsitusi bahan pangan, industri farmasi atau pengobatan. Perlu uji kelayakan sebagai yang telah ditentukan oleh FAO ataupun Departemen Kesehatan Republik Indonesia.

\section{Daftar Pustaka.}

Alif Chem. Eng., 2010, Perencanaan Pabrik Kimia, Ekstraksi Pectin, http://www.google.com, di unduh 9 Maret 2011.

Bambang, S., 1997, Budidaya Apel, Kanisius, Yogyakarta, 21.

Bhatia, B.S., Krisnamurty dan Girdhan, L., 1959, Preparation of Pectin from Raw Papaya by 
Aluminum Chloride Precipitation Method, Journal Food and Technology, London, vol. 3, 554.

Brown, G.G., 1961, Unit Operation, John Wiley and Sons, Inc., New York, 280.

Departemen Kesehatan Republik Indonesia, 1983, Risalah Simposium Penelitian Tumbuhan Obat III, Fak. Farmasi, UGM, 79-80.

FAO, 1978, Specification for Identity and Purity of Thickening Agent, Anti caking Agent, Antioxidants an Emulsifiers, dalam Food and Nutrition Paper, Food and Agriculture Organization of United Nations, Rome, 38-40.

http://www.dokterumum.net/article/senyawa-yangmengandung-pektin. html., diunduh 9 Maret 2011.
Kertesz, Z.I., 1951, The Pectin Substance, Inter Science Pub. Inc., New York, 44-71, 243-247, 295-323, 511-512.

Kirk, R.E., and Othmer, D.F., 1953, Encyclopedia of Chemical Technology, Inter science Pub. Inc., New York, vol. 14, 636-649.

Margantan, A., 2001, Banyak Makanan Berkhasiat Obat, CV. Aneka, Solo.

Suhardi, 1997, Analisa Pektin Produk Buah-buahan dan Sayur-sayuran, Fakultas Teknologi Pertanian, UGM., vol. II, 15-20.

Winarno, F.G., 1984, Kimia Pangan dan Gizi, PT. Penerbit Gramedia, Jakarta, Indonesia, 35-37.

Wirakusumah, E.S., 1995, Buah dan Sayur untuk Terapi, Penebar Swadaya, Jakarta. 